[Agr. Biol. Chem., Vol. 31, No. 4, p. 435 440, 1967]

\title{
Kinetic and Equilibrium Studies on D-Mannose-D-Fructose Isomerization Catalyzed by Mannose Isomerase from Streptomyces aerocolorigenes
}

\author{
By Yoshiyuki TAKASAKI \\ Fermentation Research Institute, Ministry of International Trade and Industry, \\ Inage, Chiba City, Japan \\ Received October 3, 1966
}

\begin{abstract}
The equilibrium constant of the isomerization reaction between D-mannose and Dfructose which is catalyzed by a mannose isomerase from Streptomyces aerocolorigenes was obtained by using three methods over the temperature range from 1 to $40^{\circ} \mathrm{C}$.

It was found that the equilibrium constant was scarcely dependent on temperature, $\Delta H$, the heat of the formation of $\mathrm{D}$-fructose from $\mathrm{D}$-mannose, being approximately zero.

The standard free energy change, $\Delta G$, and the standard entropy change, $\Delta S$, of the reaction were calculated from the equilibrium constants at various temperatures and $\Delta H$. The values of $\Delta G$ and $\Delta S$ at $25^{\circ} \mathrm{C}$ were $-650 \mathrm{cal} / \mathrm{mole}$ and $+2.2 \mathrm{cal} / \mathrm{deg} \cdot \mathrm{mole}$, respectively.

By combining these thermodynamic data with those obtained for the isomerization reaction between $\mathrm{D}$-glucose and $\mathrm{D}$-fructose reported in the previous paper, $\Delta H, \Delta G$ and $\Delta S$ for the isomerization between $\mathrm{D}$-mannose and $\mathrm{D}$-glucose were indirectly obtained to be $+2220 \mathrm{cal} / \mathrm{mole}$, $+830 \mathrm{cal} / \mathrm{mole}$ and $+4.6 \mathrm{cal} / \mathrm{deg} \cdot$ mole at $25^{\circ} \mathrm{C}$, respectively.
\end{abstract}

\section{INTRODUCTION}

Mannose isomerase catalyzes the reversible interconversion between $\mathrm{D}$-mannose and $\mathrm{D}^{-}$ fructose.

In the previous paper, ${ }^{2 \prime}$ the formation of the isomerase from Streptomyces aerocolorigenes and some of its properties were reported by the author.

This paper deals with the influence of temperature upon the equilibrium constant of the reaction catalyzed by this enzyme.

\section{EXPERIMENTAL}

Enzyme preparation. The cell-free extracts $(100 \mathrm{ml})$, which were prepared according to the method shown in the previous paper, ${ }^{2)}$ were brought to $40 \%$ saturation by the addition of solid ammonium sulfate. After removal of the precipitate by centrifugation, the

1) Y. Takasaki, This Journal, 31, 309 (1967).

2) Y. Takasaki, Report of Fer. Res. Inst., 28, 89 (1965). supernatant was brought to $60 \%$ saturation by further addition of ammonium sulfate. The precipitate was collected and dissolved in distilled water, and then dialyzed in a cellophane tube against distilled water for 24 hours. The dialyzed sample was treated with $1.8 \mathrm{ml}$ of $2 \%$ protamine and then centrifuged, and the supernatant (protein concentration, $5.6 \mathrm{mg} / \mathrm{ml}$ ) was used as a stock enzyme solution throughout this experiment.

Materials. D-Mannose and D-fructose were purchased from Shimahisa Yakuhin Co. (Japan) and Wako Junyaku Co. (Japan), respectively. The purity of these sugars was checked by measuring their specific rotations at $589 \mathrm{~m} \mu$. These were in good agreement with their specific rotations reported in the literature.

Procedure. Enzyme reactions were carried out at the temperature range of 1 to $40^{\circ} \mathrm{C}$ in a $0.05 \mathrm{M}$ phosphate buffer solution ( $\mathrm{pH} \mathrm{7.0)}$. The time course of the reaction was followed by one of the following two methods.

1) Chemical analysis method. The reaction was commenced by mixing $1.5 \mathrm{ml}$ of the stock enzyme 
solution with $1.5 \mathrm{ml}$ of substrate solution in $0.1 \mathrm{M}$ phosphate buffer solution ( $\mathrm{pH} 7.0$ ) (concentration of substrate, D-mannose or D-fructose, $0.02 \%$ ) in a test tube. At definite time intervals, $0.5 \mathrm{ml}$ of the reaction mixture was pipetted out and was poured immediately into $0.5 \mathrm{ml}$ of $0.5 \mathrm{M}$ perchloric acid to stop the reaction. The concentration of $\mathrm{D}$-fructose formed or remained was determined by the cysteine-carbazole method. ${ }^{3}$

2) Polarimetric method. The reaction was commenced by mixing $0.1 \mathrm{ml}$ of the stock enzyme solution with $1 \mathrm{ml}$ of the buffer-substrate solution (substrate, $\mathrm{D}$-mannose or $\mathrm{D}$-fructose, $0.1 \sim 1.0 \%$ in $0.05 \mathrm{M}$ phosphate buffer solution ( $\mathrm{pH} 7.0$ )) in a qualtz cuvette (optical path $10 \mathrm{~mm}$ ) in a recording-spectropolarimeter (Yanagimoto ORD-185 type), and the change in optical rotation was recorded at $300 \mathrm{~m} \mu$ as described in the preceding paper.1\} When 1 mole of D-mannose is converted into 1 mole $\mathrm{D}$-fructose, the decrease in optical rotation should be $8.98^{\circ}$ on the basis of optical rotation for $\mathrm{D}$-mannose and $\mathrm{D}$-fructose obtained at $300 \mathrm{~m} \mu$ under these conditions. The maximum sensitivity of the polarimeter-recorder system used here was $0.005^{\circ}$ (rotational angle) per $1.5 \mathrm{~cm}$ of the recorder chart.

\section{RESULTS AND DISCUSSION}

The equilibrium constant $K$ of the isomerization for the formation of $\mathrm{D}$-fructose from $\mathrm{D}$ mannose is given by the expression

$$
K=\frac{[\mathrm{D}-\text { Fructose }]}{\text { [D-Mannose }]}
$$

\section{Determination of equilibrium constant}

The equilibrium constant was determined by the following three methods, two of which were essentially the same as those described in the preceding paper. ${ }^{11}$ The third one, termed the equilibration rate method, was employed in addition in this paper.

1) Chemical analysis method. Fig. 1. shows a typical time course (studied by analytical method) of the mannose isomerase-catalyzed reaction which was carried out at $25^{\circ} \mathrm{C}$ using either pure $\mathrm{D}$-mannose or pure $\mathrm{D}$-fructose. The lower curve represents the time course

3) Z. Dische and E. Borenfreund, J. Biol. Chem., 192, $583(1951)$.

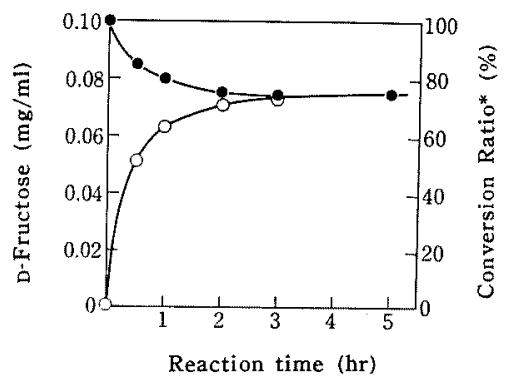

FIG. 1. Typical Time Course of Mannose Isomerase Reaction as Studied by Chemical Analysis Method

Reaction mixture

Initial substrate concentration, $10 \times 10^{-2} \%$ (for each sugar)

Phosphate buffer solution ( $\mathrm{pH} 7.0$ ), $5.0 \times 10^{-2} \mathrm{M}$

Enzyme concentration, $2.8 \times 10^{-1} \%$ (as protein) Temperature, $25^{\circ} \mathrm{C}$

$\mathrm{O}-\mathrm{D}$-Mannose (as starting substrate)

- D-Fructose (as starting substrate)

* Conveasion Ratio; $\frac{[\mathrm{D}-\text { Fructose }] \times 100}{[\mathrm{D}-\text { Mannose }]+[\mathrm{D}-\text { Fructose }]}$

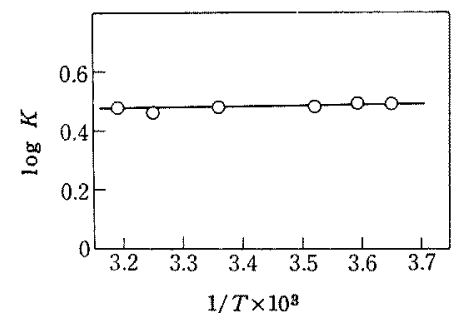

Frg. 2. Plots of $\log K$ versus $I / T$

Reaction mixture

Substrate concentration, $1.0 \times 10^{-2} \%$

Enzyme concentration, $2.8 \times 10^{-1} \%$ (as protein)

Temperature range, $1 \sim 40^{\circ} \mathrm{C}$

of formation of $\mathrm{D}$-fructose starting from pure $D$-mannose and the upper curve shows the time course of decrease in $\mathrm{D}$-fructose starting from pure $D$-fructose. From the concentrations of $\mathrm{D}$-fructose and $\mathrm{D}$-mannose at equilibrium state, the equilibrium constants were determined in such a manner as shown in the preceding paper. As a result, the equilibrium constant $K$ was estimated to be 3.0.

Fig. 2 shows a plot of logarithms of the equilibrium constants determined at several 
temperatures against reciprocals of absolute temperature.

It was found that the equilibrium constant of the D-mannose-D-fructose system is scarcely dependent on temperature. Consequently, the heat of the reaction $\Delta H$ is evaluated to be zero whithin the experimental error.

2) Kinetic method. The equilibrium constant can also be determined from the maximum velocities $(V)$ and the Michaelis constants $\left(K_{m}\right)$ of both forward and backward reactions according to Haldane's equation as described in the preceding paper.

The plot of $s / v$ versus $s$, where $v$ is the initial velocity at the substrate concentration $s$, is shown in Fig. 3.

$$
\frac{s}{v}=\frac{K_{m}}{V}+\frac{s}{V}
$$

From the intercepts on the base line of these plots, the values of $K_{m}$ for D-mannose and Dfructose were calculated to be $1.4 \times 10^{-3} \mathrm{M}$ $(0.26 \%)$ and $2.1 \times 10^{-3} \mathrm{M}(0.38 \%)$, respectively. Since the intercept on the vertical axis gives

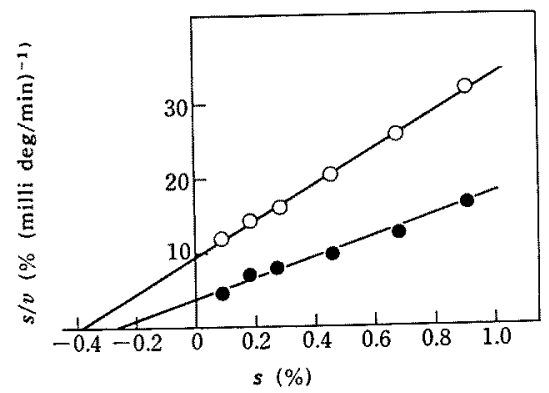

FIG. 3. Plots of $s / v$ versus $s$

Enzyme concentration, $5.1 \times 10^{-2} \%$ (as protein) Temperature, $25^{\circ} \mathrm{C}$

- D-Mannose

$O-O$ D-Fructose
$K_{m} / V$, the equilibrium constant at $25^{\circ}$ and $\mathrm{pH}$ 7.0 was estimated to be 2.6 according to Haldane's equation (equation (5) in the preceding paper $\left.{ }^{11}\right)$. This value is in reasonable agreement with the value $(3.0)$ at $25^{\circ} \mathrm{C}$ which was obtained by the chemical analysis method.

The values of $K_{m}, V, V / K_{m}$ for the forward and backward reactions and $K$ obtained by the method are summarized in Table $I$.

3) Equilibration rate method. This method is a new one devised to determine the equilibrium constant by the application of rate equation which was derived by Peller and Alberty. ${ }^{4}$

Consider a reaction involving the reversible interconversion of substrates $\mathrm{A}$ and $\mathrm{B}$ catalyzed by an enzyme $\mathrm{E}$, in which two intermediate complexes EA and EB are assumed to be involved,

$$
\mathrm{A}+\mathrm{E} \underset{k-1}{\stackrel{k_{+1}}{\rightleftarrows}} \mathrm{EA} \underset{k_{-2}}{\stackrel{k_{+2}}{\rightleftarrows}} \mathrm{BE} \underset{k_{-8}}{\stackrel{k_{+8}}{\rightleftarrows}} \mathrm{E}+\mathrm{B}
$$

where $k_{+1}, k_{+2}$ and $k_{+3}$ are the rate constants for the forward processes and $k_{-1}, k_{-2}$ and $k_{-3}$ are the rate constants for the reverse processes, respectively.

The rate of disappearance of $\mathrm{A},-d[\mathrm{~A}] / d t$, or the rate of formation of $\mathrm{B}, d[\mathrm{~B}] / d t$ (represented by $v$ ) is given by the steady-state treatment as follows:

$$
v \equiv-\frac{d[\mathrm{~A}]}{d t}=\frac{d[\mathrm{~B}]}{d t}=\frac{\frac{V_{\mathrm{A}}}{K_{\mathrm{A}}}[\mathrm{A}]-\frac{V_{\mathrm{B}}}{K_{\mathrm{B}}}[B]}{1+\frac{[\mathrm{A}]}{K_{\mathrm{A}}}+\frac{[\mathrm{B}]}{K_{\mathrm{B}}}}
$$

where $[A]$ and $[B]$ are the concentration of $A$ and $B$ at which the rate $v$ is measured,

\begin{tabular}{|c|c|c|c|c|c|c|c|}
\hline $\begin{array}{c}\text { Temperature } \\
\left({ }^{\circ} \mathrm{C}\right)\end{array}$ & $K$ & $\begin{array}{l}K_{m f} \\
(\%)\end{array}$ & $\begin{array}{l}K_{m_{b}} \\
(\%)\end{array}$ & (milli $\begin{array}{l}V_{f} \\
\mathrm{deg} / \mathrm{min})\end{array}$ & $\begin{array}{c}V_{b} \\
\text { (milli } \mathrm{deg} / \mathrm{min} \text { ) }\end{array}$ & $V_{f} / K_{m f}$ & $V_{b} / K_{m_{b}}$ \\
\hline 25 & 2.6 & 0.26 & 0.38 & 0.071 & 0.041 & 0.28 & 0.11 \\
\hline
\end{tabular}
$V_{\mathrm{A}}$ (or $V_{\mathrm{B}}$ ) and $K_{\mathrm{A}}$ (or $K_{\mathrm{B}}$ ) are the maximum

Table I. Kinetic Parameters and Equilibrium Constant of Mannose Isomerase Reaction

4) L. Peller and R. A. Alberty, J. Am. Chem. Soc., 81, 5907 (1959). 
velocity and the Michaelis constant which are obtained by the usual method starting from the pure substrate $\mathrm{A}$ (or $\mathrm{B}$ ), respectively.

The explicit expression for $K_{\mathrm{A}}, K_{\mathrm{B}}, V_{\mathrm{A}}$ and $V_{\mathrm{B}}$ in terms of $k$ 's, which would be obtained from the generalized equation given by Peller and Alberty, is not necessary for the present purpose.

By using the Haldane relationship

$$
K=\left(\frac{V_{\mathrm{A}}}{K_{\mathrm{A}}}\right) /\left(\frac{V_{\mathrm{B}}}{K_{\mathrm{B}}}\right)=R_{\mathrm{A}} / R_{\mathrm{B}}
$$

where $R_{\mathrm{A}}=V_{\mathrm{A}} / K_{\mathrm{A}}, R_{\mathrm{B}}=V_{\mathrm{B}} / K_{\mathrm{B}}$, Equation (4) becomes

$$
v=\frac{R_{\mathrm{A}}([\mathrm{A}]-[\mathrm{B}] / K)}{1+\frac{[\mathrm{A}]}{K_{\mathrm{A}}}+\frac{[\mathrm{B}\rfloor}{K_{\mathrm{B}}}}
$$

Let $A$ be the deviation of the substrate concentration $[\mathrm{A}]$ and $[\mathrm{B}]$ from their equilibrium values $[\mathrm{A}]_{e}$ and $[\mathrm{B}]_{e}$, then

$$
\begin{aligned}
& {[\mathrm{A}]=[\mathrm{A}]_{e}+\Delta} \\
& {[\mathrm{B}]=[\mathrm{B}]_{e}-\Delta} \\
& {[\mathrm{A}]+[\mathrm{B}]=[\mathrm{A}]_{e}+[\mathrm{B}]_{e}=[\mathrm{C}]_{\text {total }}}
\end{aligned}
$$

where $[\mathrm{C}]_{\text {total }}$ is the sum of the substrate concentrations of A and B. Equation (6) can be rewritten by the use of equation (7) as follows:

$$
v=\frac{[R]_{\mathrm{A}}[\mathrm{C}]_{\text {total }}\left\{(1+K) f_{\mathrm{A}}-1\right\} / K}{\left(1+\frac{[\mathrm{A}]_{e}}{K}+\frac{[\mathrm{B}]_{e}}{K}\right)+\Delta\left(\frac{1}{K_{\mathrm{A}}}-\frac{1}{K_{\mathrm{B}}}\right)}
$$

where $f_{\mathrm{A}}$ is the mole fraction of $\mathrm{A}$.

$$
f_{\mathrm{A}}=\frac{[\mathrm{A}]}{[\mathrm{A}]+[\mathrm{B}]}=\frac{[\mathrm{A}]}{[\mathrm{C}]_{\text {total }}}
$$

If the second term of the denominator of equation (8) can be neglected with the first term, i. e.,

$$
|H| \ll[\mathrm{A}]_{e},[\mathrm{~B}]_{e} \text { or } K_{\mathrm{A}} \fallingdotseq K_{\mathrm{B}}
$$

equation (8) reduces to

$$
v=\frac{[R]_{\mathrm{A}}[\mathrm{C}]_{\mathrm{total}}\left\{(1+K) f_{\mathrm{A}}-1\right\}}{K\left(1+\frac{[\mathrm{A}]_{e}}{K_{\mathrm{A}}}+\frac{[\mathrm{B}]_{e}}{K_{\mathrm{B}}}\right)}
$$

Thus for a constant $[\mathrm{C}]_{\text {total }}, v$ is a linear function of $f_{\mathrm{A}}$, so far as the conditions given by equation (10) is fulfilled; i. e., generally using $[\mathrm{A}]$ and $[\mathrm{B}]$ near the equilibrium values $[\mathrm{A}]_{e}$ and $[\mathrm{B}]_{e}\left(|\Delta| \ll[\mathrm{A}]_{e},[\mathrm{~B}]_{e}\right)^{*}$

The equilibrium constant $K$ can be obtained from $f_{\mathrm{A}}$, for which $v$ becomes zero. Thus,

$$
\begin{aligned}
& (1+K) f_{\mathrm{A}}-1=0 \quad(\text { for } v=0) \\
& K=\frac{1}{f_{\mathrm{A}}}-1
\end{aligned}
$$

Practically, this value of $f_{\mathrm{A}}$ may be obtained by plotting $v$ against various values of $f_{\mathrm{A}}$ (near equilibrium as possible). The point of intersection of the straight line of the plot with the $f_{\mathrm{A}}$ axis will give the value of $f_{\mathrm{A}}$ for $v=0$.

This provides a useful means for determining $K$ in a great accuracy. The accuracy is the best among the three methods employed in this study. The closeness of the values of $K_{\mathrm{A}}$ and $K_{\mathrm{B}}$ in this case ( $K_{m}$ 's of D-mannose and $\mathrm{D}$-fructose described above) provides the advantage to use relatively wide range of $\Delta$.

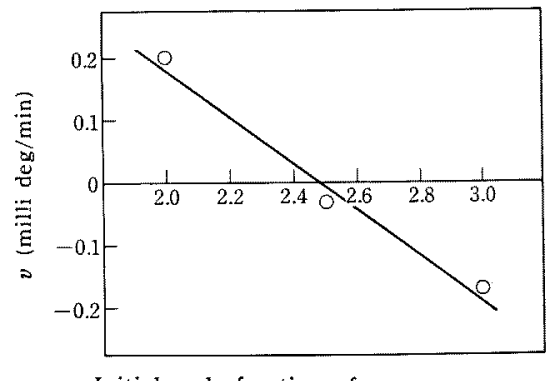

FIG. 4. Effect of Initial Mole Fraction of D-Mannose on Rate Velocity

Reaction mixture

Total substrate concentration [C]

Phosphate buffer solution (pH 7.0), $4.5 \times 10^{-2} \mathrm{M}$

Enzyme concentration, $5.1 \times 10^{-2} \%$

Temperature, $39.4^{\circ} \mathrm{C}$

* Equation (11) can easily be written also in the form, for which $v \propto \Delta$ for small $\Delta ; v$ is proportional to the deviation from equilibrium and becomes zero at equilibrium. 


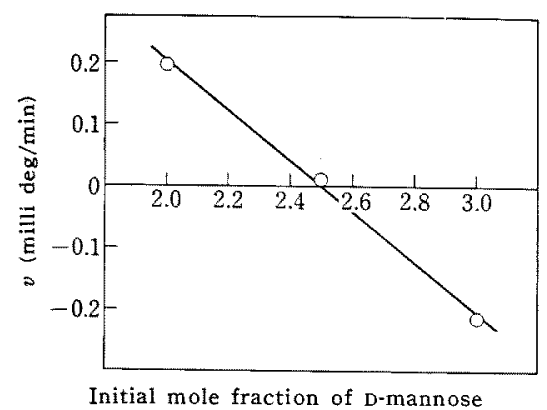

FIG. 5. Effect of Initial Mole Fraction of D-Mannose on Rate Velocity

Reaction mixture

(Total substrate concentration $[\mathrm{C}]_{\text {total }}, 1.82 \%$

$\left\{\right.$ Phosphate buffer solution (pH 7.0), $4.5 \times 10^{-2} \mathrm{M}$

Enzyme concentration, $5.1 \times 10^{-2 \%}$

Temperature, $25^{\circ} \mathrm{C}$

This results of this method are shown in Figs. 4 and 5, in which the initial rate $v$ determined polarimetrically is plotted against the mole fraction of $\mathrm{D}$-mannose of the starting mixed substrate solution.

The total concentration $[\mathrm{C}]_{\text {total }}$ was fixed at 1.82\%. The values of $K$ thus determined were 3.00 and 3.03 at $39.4^{\circ} \mathrm{C}$ and $25^{\circ} \mathrm{C}$, respectively, which are in good agreement with those obtained by the chemical analysis method.

II. Thermodynamic quantities of isomerization of D-mannose to D-fructose

The standard free energy change accompanying the reaction in which $\mathrm{D}$-fructose is formed from D-mannose was calculated from the $K$ values. Since $\Delta H$ of the reaction is zero, the standard entropy change $\Delta S$ of the reaction can be given by using the following equation (13)

$$
\Delta S=\frac{\Delta H-\Delta G}{T} \fallingdotseq-\frac{\Delta G}{T}
$$

The thermodynamic quantities obtained at various temperatures are listed in Table II.

In the preceding paper, ${ }^{11}$ the thermodynamic quantities accompanying the process in which $\mathrm{D}$-fructose is formed from $\mathrm{D}$-glucose were de-
TABLE II. Thermodynamic Quantities of IsoMERIZATION OF D-MANNOSE TO D-FRUCTOSE AT VARIOUS TEMPERATURES

$\begin{array}{ccccc}\begin{array}{c}\text { Temperature } \\ \left({ }^{\circ} \mathrm{C}\right)\end{array} & K & \begin{array}{c}\Delta H \\ (\mathrm{cal} / \mathrm{mol})\end{array} & \begin{array}{c}\Delta G \\ (\mathrm{cal} / \mathrm{mol})\end{array} & \begin{array}{c}\Delta S \\ (\mathrm{cal} / \mathrm{deg} . \\ \mathrm{mole})\end{array} \\ 1 & 3.1 & 0 & -610 & +2.2 \\ 6 & 3.1 & 0 & -630 & +2.2 \\ 11 & 3.0 & 0 & -620 & +2.2 \\ 25 & 3.0 & 0 & -650 & +2.2 \\ 35 & 2.9 & 0 & -650 & +2.1 \\ 40 & 3.0 & 0 & -680 & +2.2\end{array}$

TABLE III. Thermodynamic QUantities of IsoMERIZATION OF D-GLUCOSE TO D-MaNNOSE AT $25^{\circ} \mathrm{C}$

$\begin{array}{ccccc}\begin{array}{c}\text { Temperature } \\ \left({ }^{\circ} \mathrm{C}\right)\end{array} & K & \begin{array}{c}\Delta H \\ (\mathrm{cal} / \mathrm{mole})\end{array} & \begin{array}{c}\Delta G \\ (\mathrm{cal} / \mathrm{mole})\end{array} & \begin{array}{c}\Delta S \\ (\mathrm{cal} / \mathrm{deg} .) \\ \mathrm{mole})\end{array} \\ 25 & 0.24 & +2220 & +830 & +4.6\end{array}$

termined by the use of glucose isomerase from Streptomyces sp. By combining these values and the data given in Table II, the thermodynamic quantities of the reaction in which D-mannose is formed from D-glucose, which cannot be studied directly due to the lack of enzyme specifically catalyzing the reaction, can be calculated. The results are listed in Table III.

It should be mentioned that the terms, $\mathrm{D}$ glucose, D-mannose and D-fructose, used in this study and the preceding paper, represent the equilibrium mixture of anomers ( $\alpha$ and $\beta$ ) of each sugar, the interconversion equilibrium of which had been actually established in aqueous solution before the measurement was commenced. The reaction of enzyme-catalyzed isomerization between the sugars was conducted in such a low rate compared with that of the $\alpha-\beta$ anomerization that the rate-limiting step is the isomerization itself. The initial and final states implied in the description of thermodynamic quantities correspond, therefore, the equilibrium mixture of $\alpha$ - and $\beta$ anomers of each sugar.

Acknowledgments. This study was carried out at the University of Osaka Prefecture. 
The author wishes to express his sincere thanks author also wishes to thank Dr. Osamu Tato Prof. Sôzaburo Ono and Dr. Keitaro Hiro- nabe, Director of 2nd Division of Industrial mi of the University for their unfailing guid- Microbiology of Fermentation Research Inance throughout the course of this study. The stitute for encouragement of this study. 